Anfal A Al-Ani

BDS, MSc (Asst. Lec.)

\section{Diagnostic and Therapeutic Guidance for Class II Malocclusion Treatment}

\author{
Dept of Pedod, Orthod, and Prev Dentistry \\ College of Dentistry, University of Al-Mustansyria
}

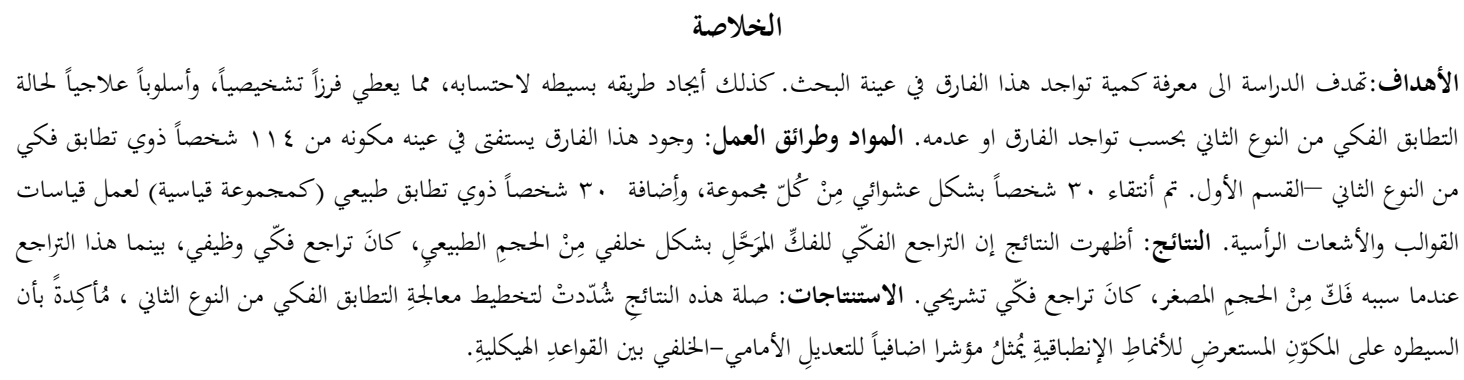

ABSTRACT

Aims: to detect the prevalence of PTID among our Class II sample and to establish a simple method to assess it, providing a diagnostic and therapeutic guidance for the Class II malocclusion treatment. Materials and methodes: The existence of (PTID) was investigated among 114 Class II div.I adults. Randomly selected 30 subjects from each group, adding 30 Class I subjects (as a control group) for cast and Cephalometric measurements. Resultes: Mandibular retrusion with posteriorly displaced mandible of normal size, was of functional mandibular retrusion, while this retrusion when caused by micrognathic mandible, was of anatomic mandibular retrusion. Conclusions: The relevance of these findings was stressed for the treatment planning of Class II subjects, confirming that controlling the transverse component of the occlusal patterns represent an additional input signal for the anteroposterior adjustment between the skeletal bases.

Key words: Posterior transverse interarch discrepancy, functional and anatomic mandibular retrusion.

Al-Ani AA. Diagnostic and Therapeutic Guidance for Class II Malocclusion Treatment. Al-Rafidain Dent J. 2013; 13(1): 147-153.

Received 14/11/2011

Sent to Referees: $15 / 11 / 2011$

Accepted for Publication:7/2/2012

\section{INTRODUCTION}

Class II is a frequent type of malocclusion which could be presented as maxillary protrusion, mandibular retrusion or combinations. In all Class II subjects, the maxillary- mandibular positioning on the sagittal plane can be described as a distal relationship of the mandible to the maxilla. ${ }^{(1)}$ As the normal dental arch has smaller anterior than posterior transverse dimensions, the distal relationship of the mandible to the maxilla of Class II may show hypothetically anterior and posterior gaps between maxillary and mandibular arches which must effect directly the mastication. This condition is not really existed due to the natural harmonization between the in and out oro-facial muscular forces and dental arches compensation takes place, ${ }^{(2)}$ meaning that when examining each arch alone in those with Class II malocclusion often shows a transverse discrepancy between upper and lower dental arches, gen- erally attributed to a reduction in maxillary width. The constriction of the upper arch can be interpreted as transverse compensation to mandibular retropositioning. ${ }^{(3)}$ Such constriction of the upper arch transverse dimension required to be diagnosed whenever mandibular advancement is planned during treatment. ${ }^{(4,5)}$

According to some recent studies, there is a controversy about the existence, the amount and the location of this constriction, but in general, treating subjects with Class II need to restore the amount of narrowing in the maxillary arch, when found, and this must be stressed for the treatment planning. ${ }^{(6,7)}$ It must be detected especially for those who need to be treated with functional appliances this can give better results and less relapse. ${ }^{(8,9)}$ The preferable type of functional appliance in this situation is that which free the transverse dimension to be restored, as the functional 
regulator ("Frankel" functional appliance)..$^{(10,11)}$

AIMS

The aims of this study were:

1. To classify Class II malocclusions according to the presence or absence of (PTID), defining a simple method for the (PTID) assessment.

2. Comparing the "with" and "without" (PTID) Class II groups between each others and with Class I group for:

a. Absolute intermolar width measurements; to provide a diagnostic and therapeutic guidance in the early approach of Class II malocclusion treatment.

b. Cephalometric angular and linear measurements; for craniofacial assessment.

\section{MATERIALS AND METHODS}

The sample used in this study was from the patients who attended AlDawoodi health center for dental care in Baghdad/Al-karkh. From their clinical examination and the diagnostic routine Cephalometric x-ray, 114 subjects (43 males-71 female) of 17-25 years (mean age $21.15 \pm 1.92$ years) who classified as Class II div.I according to the following criteria: on centric occlusion the subjects showed clinically bilateral Class II 1 st permanent molar relationship (Angle clas-

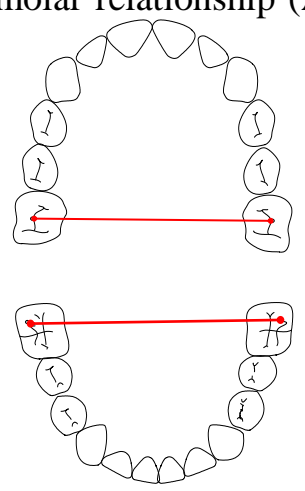

In class I molar relationship, the distobuccal cusp of the 1st mandibular molar occludes in the central fossa of the 1 st maxillary molar, consequently in class I subjects, maxillary and mandibular intermolar widths are equal and (PTID) is zero; while in class II subjects, a negative sign indicates narrower maxillary than mandibular arch width (Figure1). sification) and bilateral Class II canine relationship, while cephalometriclly they had mandibular retrusion and protruded maxillary incisors, with no maxillary prognathisim (normal SNA and increased ANB angles).

Another 30 Class I subjects (15 males15 female) of the same age group were selected from the patients' escorts and companies, having the criteria of normal occlusion, ${ }^{(6,11)}$ used as a control group in this study.

The whole sample including the control group subjects had upper and lower full permanent dentition with or without the 3rd molar eruption, with no mesial rotation of the 1 st permanent molars. Impressions for upper and lower dental casts were taken.

Based on Moorrees criteria, ${ }^{(12)}$ measurements carried out on dental casts by dial vernier calipers to the nearest 0.01 $\mathrm{mm}$, as the following:

(1) Maxillary intermolar width; the distance between the central fossae of the right and the left maxillary molars.

(2) Mandibular intermolar width; the distance between the tips of the distobuccal cusps of the right and the left mandibular molars.

(3) PTID; is the deference between the 1 st and 2nd measurements (Figure 1).

Figure (1): Measurements on maxillary and mandibular dental casts of Class II div I with PTID:As maxillary and mandibular intermolar width; PTID is calculated as the difference between them $(-5$ $\mathrm{mm})$

This method of measurement was advocated by some researchers as they deal with class II cases. ${ }^{(2-5)}$

The 114 class II subjects of the sample were separated into two groups according to the existence of (PTID), (Table 1) identifying its prevalence in the sample. 
Table (1): The Class II sample "cast analysis" due to presence or absence of PTID.

\begin{tabular}{cccc}
\hline Sex & with PTID & without PTID & Total \\
\hline \multirow{\lambda}{*}{} & 19 & 24 & 43 \\
+ & 27 & 44 & 71 \\
Total & 46 & 68 & 114 \\
\hline
\end{tabular}

Selection of 30 subjects randomly from each group of with and without PTID as (Group 1) and (Group 2) respectively, in addition to the 30 Class I subjects of the control group, having cast and cephalometric measurements. The three groups of the sample were with equal genders $(15 \hat{0}$ 15 ㅇ) and at the same age group.

Fixing the group number and made it with equal genders for each group, was going on with the limited number of the available control group. Matching the three groups in number, sex and age aims to have easer statistics, clearer differences and more obvious PTID results.

The standardized lateral cephalograms of the sample $(n=90)$ were taken with the same x-ray device and by the same technician. They were subjected to angular and linear measurements, for the relation of the basal bones of the jaws with the cranial base.The Cephalometric measurements (Figure 2) were:
Anterposterior relationships:

Maxillary sagittal position: SNA angle. Mandibular sagittal position: SNB angle. Maxillo-mandibular sagittal discrepancy: ANB angle.

Antero-posterior position of the glenoid fossa: N-S-TM angle.

Vertical relationships:

Maxillary inclination relative to the cranial base: NL/NSL angle

Mandibular inclination relative to the cranial base: ML/NSL angle

Maxillo-mandibular vertical relationship: : NL/ML angle

Gonial angle:Ar-Go-Me angle

Mandibular dimensions:

Length of the mandibular body: Go-Pg Length of the mandibular ramus: Co- Go Total mandibular length: Co-Pg

Definitions for the points and planes are those given by Bjork, ${ }^{(13)}$ Riolo et al. ${ }^{(14)}$ and Harvold. ${ }^{(15)}$

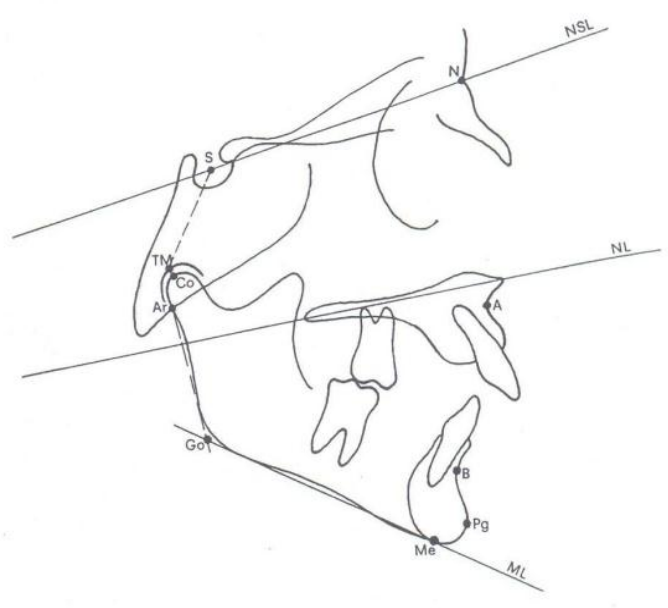

Figure (2): Cephalometric land marks and planes.

Statistical analysis: One way analysis of variance was carried out for the independent samples $(p<0.05)$, also the statistical significance of intergroup difference was assessed $(p<0.01)$. Method error: Method error for dental casts and cephalometric measurements were assessed on
30 subjects randomly selected from the study sample; for which cast and tracing measurements were repeated by the same investigator to test the reliability of the method. Measurement errors were determined using the Dahlberg's formula: ${ }^{(16)}$

$\sqrt{ }\left(\sum \mathrm{D} 2 / 2 \mathrm{~N}\right)$ 
Where $\mathrm{D}$ is the difference between each of the two re-measured values, and $\mathrm{N}$ is the number of the sample which were double measured $(\mathrm{N}=30)$. Method error for the cast arch width measurements was $0.16 \mathrm{~mm}$, for the cephalometric angular measurements ranged from $0.43^{\circ}$ to $0.88^{\circ}$, and for cephalometric linear measurements was from 0.77 to $0.87 \mathrm{~mm}$.

\section{RESULTS}

Descriptive statistics for the three groups (Class II Group 1, Class II Group 2 , and Class I control group) were shown in (Table 2-a) for the cast measurements and in (Table 2-b) for the lateral cephalometric measurements.

Table (2-a): Descriptive statistics of dental cast measurements for Class II Groups and the Class I Group.

\begin{tabular}{|c|c|c|c|c|c|c|c|c|c|c|c|c|c|}
\hline & \multirow[t]{2}{*}{ Measurements } & \multicolumn{4}{|c|}{ Class II (Group 1) } & \multicolumn{4}{|c|}{ Class II (Group 2) } & \multicolumn{4}{|c|}{$\begin{array}{c}\text { Class I (Control } \\
\text { Group) }\end{array}$} \\
\hline & & Mean & SD & SE & $\begin{array}{l}\text { Me- } \\
\text { dian }\end{array}$ & $\underset{\mathbf{n}}{\mathrm{Mea}}$ & SD & SE & $\begin{array}{l}\text { Me- } \\
\text { dian }\end{array}$ & $\begin{array}{c}\text { Mea } \\
\text { n }\end{array}$ & SD & SE & $\begin{array}{l}\text { Me- } \\
\text { dian }\end{array}$ \\
\hline \multirow{3}{*}{ 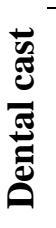 } & $\begin{array}{l}\text { Max. intermolar } \\
\text { width }\end{array}$ & 43.1 & 2.72 & 0.49 & 43.3 & 46.9 & 2.95 & 0.53 & 46.5 & 46.96 & 2.32 & 0.42 & 47.15 \\
\hline & $\begin{array}{l}\text { Mand. intermo- } \\
\text { lar width }\end{array}$ & 46.49 & 2.5 & 0.45 & 46.2 & 46.85 & 2.97 & 0.54 & 46.5 & 46.93 & 2.33 & 0.42 & 47.1 \\
\hline & PTID & -3.34 & 1.79 & 0.32 & -2.95 & 0.04 & 0.09 & 0.01 & 0 & 0.03 & 0.09 & 0.01 & 0 \\
\hline
\end{tabular}

Table (2-b): Descriptive statistics for Class II Group 1, Class II Group 2, and Class I Group for the angular and linear lateral cephalometric measurements.

\begin{tabular}{|c|c|c|c|c|c|c|c|c|c|c|c|c|c|c|}
\hline & \multirow{2}{*}{\multicolumn{2}{|c|}{ Measurements }} & \multicolumn{4}{|c|}{ Class II (Group 1) } & \multicolumn{4}{|c|}{ Class II (Group 2) } & \multicolumn{4}{|c|}{ Class I (Control Group) } \\
\hline & & & Mean & SD & SE & Median & Mean & SD & SE & Median & Mean & SD & SE & Median \\
\hline \multirow{11}{*}{ 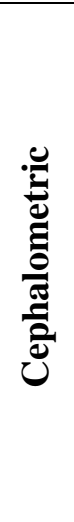 } & SNA & (degrees) & 79.15 & 2.92 & 0.53 & 78.5 & 80.03 & 3.75 & 0.68 & 80.5 & 79.98 & 3.44 & 0.62 & 80.25 \\
\hline & SNB & & 73.63 & 2.6 & 0.47 & 73.5 & 73.86 & 3.32 & 0.6 & & 76.88 & 3.21 & 0.58 & 77.25 \\
\hline & ANB & & 5.55 & 1.51 & 0.27 & 5 & 6.17 & 2.27 & 0.41 & 6.5 & 3.1 & 0.87 & 0.15 & 3 \\
\hline & NSTM & ( & 129.98 & 3.25 & 0.59 & 130.75 & 130.6 & 3.34 & 0.61 & 131 & 129.7 & 3.66 & 0.66 & 130 \\
\hline & ML/ NSL & & 32.31 & 6.42 & 1.17 & 31.75 & 32.9 & 5.65 & 1.03 & 32 & 33.78 & 4.94 & 0.9 & 32.75 \\
\hline & $\mathrm{NL} / \mathrm{N}$ & & 7.68 & 2.17 & 0.39 & 75 & 8.1 & 2.23 & 0.04 & 8 & 7.96 & 3.37 & 0.61 & 8 \\
\hline & NL/ ML & & 24.63 & 6.46 & 1.17 & 24 & 24.8 & 5.48 & 1 & 24 & 25.85 & 4.2 & 0.76 & 26 \\
\hline & Ar-Go-Me & (degrees) & 121.98 & 6.87 & 1.25 & 123 & 120.4 & 5.17 & 0.94 & 120 & 123.63 & 6.53 & 1.19 & 124 \\
\hline & Go-Pg & & 81.66 & 4.65 & 0.84 & 81.25 & 76.4 & 4.45 & 0.81 & 76 & 82.4 & 5.88 & 1.07 & 82.25 \\
\hline & & & 61.96 & 6.41 & 1.17 & 61.25 & 55.16 & 4.32 & 0.79 & 55 & 62.6 & 4.67 & 0.85 & 61 \\
\hline & Co-Pg & $(\mathbf{m m})$ & 112.83 & 5.56 & 1.01 & 111.5 & 108.73 & 5 & 0.91 & 108 & 114.6 & 5.89 & 1.07 & 113.5 \\
\hline
\end{tabular}

Dental cast measurements:

Maxillary intermolar width was significantly narrower in (Class II Group 1) when compared to the other two groups, where as no significant differences were assessed between (Class II Group 2, and Class I control group), while for mandibular intermolar width, no significant differences were assessed between the three groups. The average value for (PTID) in Class II group1 (Table 2-a) was $-3.34 \mathrm{~mm}$ (minimum $-2.2 \mathrm{~mm}$, maximum $-5.4 \mathrm{~mm}$ ).

Student's t-Test determined the significance of the upper and lower inter 1st molar dimensions between Class I and the Class II groups, for both genders (Table $3 \& 4)$. 
Table (3): Statistical comparison (Student's t-Test) for the inter 1st molar dimensions of the upper and lower dental arch between Class I and the Class II groups for both genders.

\begin{tabular}{cllcccc}
\hline & & \multicolumn{2}{c}{ Class I (Control } & \multicolumn{2}{c}{ Class II } \\
Group) & \multicolumn{2}{c}{ (Group1\&2) } & \\
Dimension & \multicolumn{1}{c}{ Sex } & Mean & SD & Mean & SD & T \\
\hline Upper inter 1st mo- & Male $(\mathbf{n = 1 5})$ & 49.21 & 3.58 & 45.77 & 2.53 & $* *$ \\
lar & Female(n=15) & 45.24 & 2.81 & 43.45 & 2.09 & $* *$ \\
Lower inter 1st mo- & Male (n=15) & 48.91 & 2.81 & 46.25 & 2.03 & $*$ \\
lar & Female(n=15) & 45.12 & 2.58 & 44.97 & 2.21 & $*$ \\
\hline * Significant at 5\%; ** Significant at 1\% & & & & &
\end{tabular}

Table (4): Statistical comparison (Student's t-test) for the inter 1st dimensions of the upper and lower dental arch between both genders for class I and Class II groups.

\begin{tabular}{ccccccc}
\hline & & \multicolumn{2}{c}{ Male $(\mathbf{n}=15)$} & \multicolumn{2}{c}{ Female $(\mathbf{n}=15)$} & \\
\hline & Dimension & Mean & SD & Mean & SD & T \\
Class I & upper inter 1st molar & 49.21 & 3.58 & 45.24 & 2.81 & $*$ \\
Control & & & & & & \\
Group & lower inter 1st molar & 48.91 & 2.81 & 45.12 & 2.58 & $*$ \\
Class II & upper inter 1st molar & 45.77 & 2.53 & 43.45 & 2.09 & $* *$ \\
Group1\&2 & lower inter 1st molar & 46.25 & 2.33 & 44.97 & 2.81 & NS \\
\hline
\end{tabular}

NS: not significant; * Significant at 5\%; ** Significant at $1 \%$

There was significant difference (Table 3) between "Class I" and the "Class II groups" for the different genders in the upper arch (significant, $P<.05$ ), while in the lower arch they were significant at $(P$ $<.01)$. Table 4 reveals that "Class I" upper and lower inter 1st molar dimensions showed significant difference between both genders (significant, $P<.05$ ), while in "Class II groups" the upper arch showed significant difference between the genders (significant, $\mathrm{P}<.05$ ), and the lower arch showed no gender difference (nonsignificant,$P<.05)$.

\section{Cephalometric measurements}

Table 2-b reveals no mention differences for the sagittal position of the maxilla (SNA angle) existed between the three groups (basal criteria of the sample selection). The mandible was retruded in "Class II groups" (greater ANB angle) when compared with the "Class I" control group, whereas very small differences for the SNB were recorded between the "Class II group 1 (mean 81.66)" and "Class II group 2 (mean 81.25)" groups .

Very small differences among the three groups were recorded for the position of the glenoid fossa (NSTM 129.98, $130.75^{\circ}, 129.7^{\circ}$ for Class II (group1),Class II (group 2) and Class I (Control group) respectively), also for any of the measurements of the vertical skeletal relationship. Mandibular body length and total mandibular length recorded smaller values in "Class II group 1" when compared to the other two groups, while no great differences for the length of mandibular ramus (Co-Go) were found between the three groups.

\section{DISCUSSION}

Clinical examination of 114 Class II subjects with mandibular retrusion revealed the existence of transverse discrepancy between dental arches in some of these cases as shown in (Table 1). This method of measurements was advocated by some researchers as they deal with class II cases ${ }^{(2-5)}$ It is also going on with Staley et al. ${ }^{(17)}$ who extensively assessed the transverse maxillary deficiency and posterior cross bite tendency in an adult Class II sample when compared with Class I adult sample

Prior investigations for the transverse dimensions for the dental arches in Class II malocclusion have pointed out a reduction in maxillary arch width (Table 2-a) and a tendency to posterior crossbite in an adult Class II sample. ${ }^{(6-11)}$ The problem seems to be more involved during child- 
hood and adolescence as the longitudinal study which is carried out by Frohlich ${ }^{(3)}$ and by Moorrees. ${ }^{(12)}$

The current study can identify two subgroups for Class II division I malocclusion, which are "with" and "without" (PTID) groups and the results led us to analyze the skeletal features of each of these two Class II groups.

Generally different genders have significant differences for the posterior transverse dimensions of the dental arches in Class I and II groups (Table 3). The nonsignificant difference of the lower dental arches in Class II groups between males and females could be something found in the sample of this study (Table 4) which is not going on with Petrovic et al.studies. ${ }^{(18,}$ 19)

The comparison between both Class II groups and Class I control group (Table 2b) reveals no significant differences for the sagittal position of the maxilla. Moreover, the mandibular intermolar width was not significantly different among the three groups, that is because there is difference but not significant between mandibular intermolar widths of both Class II groups. The analysis of mandibular dimensions showed significantly smaller body length and total mandibular length in Class II Group 1 when compared to the other two groups, while the three groups were homogeneous as to antero-posterior position of the glenoid fossa and the vertical relationships (no significant differences for the length of mandibular ramus were found between the three groups).These results were going on with the results of many previous studies. ${ }^{(5-9)}$

Staley et al ${ }^{(17)}$ hypothesized that maxillary posterior teeth in subjects with class II div I malocclusions tend to incline palatally -with age- to compensate for the increased "buccal overjet" and the compensatory perioral muscle activity. According to this, one could speculate that an untreated class II malocclusion without PTID in the mixed dentition can result in a class II malocclusion with PTID in the permanent dentition, the condition then could be much worse. ${ }^{(17-21)}$

\section{CONCLUSIONS}

The existence of two groups of Class II div I malocclusion according to transverse interarch relationship calls for the following differential treatment strategies:

Class II malocclusions with PTID, need a preliminary calculated expansion of the maxillary arch. Subsequently the sagittal positioning of the mandible should be monitored, and a forward repositioning of the lower jaw may take place spontaneously. If not, functional forward guidance of the mandible has to be attained.

Class II malocclusions without PTID do not need an early treatment phase of maxillary expansion; the aim of the therapy is the attempting to increase the total length of the mandible. Condylar cartilage growth should be stimulated through proper functional appliance.

Finally this study confirmed the rule of occluson in the control of maxillomandibular skeletal relationships, it should be stressed that the "transverse component" of the occlusal patterns represents an additional input signal for the anteroposterior adjustment between the skeletal bases.

\section{REFERENCES}

1. McNamara JA Jr. Components of Class II malocclusion 8-10 years of age. Angle Orthod 1981; 51:177-202.

2. Tollaro I,Baccetti T, Franchi L,Tanasescu $\mathrm{CD}$. Role of posterior transverse interarch discrepancy in Class II div I malocclusion during the mixed dentition phase. Am J Orthod Dentofacial Orthop. 1996; 110:417-422.

3. Frohlich FJ. A longitudinal study of untreated Class II type malocclusion. Trans Eur Orthod Soc 1961; 37:137-59.

4. Baccetti T, Franchi L, McNamara JA Jr, Tollaro I. Early dentofacial features of Class II malocclusion: a longitudinal study from the deciduous through the mixed dentition. Am J Orthod Dentofacial Orthop. 1997; 111:502-509.

5. Bishara SE, Jakopsen JR, Treder J, Nowak A. Arch width changes from 6 weeks to 45 years of age. Am J Orthod Dentofacial Orthop.1997; 111:401-409.

6. Uysal T, Memili B, Usumez S, Sari Z. Dental and alveolar arch widths in normal 
occlusion, Class II division I and Class II division II. Angle Orthod.2005; 75:941947.

7. Walkow TM, Peck S. Dental arch width in Class II division 2 deep-bite malocclusion. Am J Orthod Dentofacial Orthop. 2002; 122:608-613.

8. Filho OG, Ferrari FM Jr, Ozawa TO.Dental arch dimensions in Class II, division I malocclusions with mandibular deficiency. Angle Orthod.2008; 78(3):466474.

9. Lux CJ, Conradt C, Burden D, Komposch G. Dental arch widths and mandibularmaxillary base widths in Class II malocclusions between early mixed dentition and permanent dentition. Angle Orthod.2003; 73:674-685.

10.Alarashi M, Franchi L, Marinelli A, Defraia E. Morphometric analysis of the transverse dentoskeletal features of Class II malocclusions in mixed dentition. Angle Orthod.2003; 73:21-25.

11.Sayin MO, Turkkahraman H. Comparison of dental arch and alveolar widths of patiants with Class II, division I malocclusion and subjects with Class I ideal occlusion. Angle Orthod.2004; 74:356-360.

12. Moorrees CFA, Chadha JM. Available space for the incisors during dental development- a growth study based on physiologic age. Angle Orthod 35:12-22, 1965.

13.Bjork A. The face in profile. Sven Tandik Tidskr.1947; 40: Suppl.

14.Riolo ML, Moyers RE, McNamara JA, Hunter WS. An atlas of craniofacialgrowth: Cephalometric standards from the University School Growth Study. Monograph 2. Ann Arbor; Center for human Growth and Development, University of Mechigan, 1974.

15. Harvold EG. The activator in interceptive orthodontics. St Louis: CV Mosby, 1974.
16.Dahlberg G. Statistical methods for medical and biological students. New York: Interscience Publications, 1940.

17.Staley RN, Stuntz WR, Peterson LC. A comparison of arch width in adults with normal occlusion and adults with Class II, division I malocclusion. Am J Orthod. 1985; 88:163-9.

18.Petrovic A, Stutzmann J. Further investigations into the functioning of the "comparator" of the servosystem (respective positions of the upper and lower dental arches) in the control of the condylar cartilage growth rate and of lengthening of the jaw. In McNamara JA Jr, ed. The biology of occlusal development. Monograph 6 . Craniofacial Growth Series. Ann Arbor; Center for human Growth and Development, University of Mechigan, 1977.

19.Petrovic A, Stutzmann J, Lavergne J. Mechanisms of craniofacial growth and modus operandi of functional appliances: a cell-level and cybernetic approach to the orthodontic decision making, In Carlson DS, ed. Craniofacial growth theory and orthodontic treatment. Monograph 23. Ann Arbor; Center for human Growth and Development, University of Mechigan, 1990.

20.McNamara JA Jr, Bryan FA. Long-term mandibular adaptations to protrusive fuction: An experimental study in Macacca mulatta. Am J Orthod Dentofacial Orthop.1987; 92:98-108.

21.Stutzmann J, Petrovic A. Role of the lateral pterygoid muscle and of the menisco-tempromandibular frenum in the spontaneous growth of the mandible and in the growth stimulated by postural hyperpropulsor: an experimental study in young rat. Am J Orthod Dentofacial Orthop.1990; 97: 381-92. 